\title{
Cellular immunity to Hodgkin's splenic tissue measured by leucocyte migration inhibition
}

\author{
B W HANCOCK, LESLEY BRUCE, JOHN RICHMOND
}

British Medical fournal, 1976, 1, 556-557

\section{Summary}

Patients with lymphoreticular malignancy were shown by a leucocyte migration inhibition technique to have cellular immunity to Hodgkin's splenic tissue. Migration was significantly inhibited in 31 out of 55 patients with Hodgkin's lymphoma and 19 out of 39 patients with other types of lymphoma. Inhibition was also shown in only three out of 29 patients with other malignancy, one out of 23 normal volunteers, and one out of 25 patients with non-malignant disease. The splenic factor that inhibits leucocyte migration, which has yet to be isolated and identified, may be a helpful diagnostic tool in patients with suspected lymphoma.

\section{Introduction}

Recent reports have suggested that there are tumour-associated antigens in Hodgkin's disease. ${ }^{1-3}$ We have studied sensitisation of lymphocytes to splenic tissue from patients with Hodgkin's disease by an in-vitro leucocyte migration inhibition technique. We report here our preliminary findings.

\section{Patients and methods}

Of the 171 patients studied 55 had Hodgkin's disease, 39 had other types of lymphoma, 29 had non-lymphomatous malignancy, 25 had non-malignant illness (usually coronary and cerebrovascular disease), and 23 were healthy volunteers. Blood samples were taken before treatment from all patients with malignancy.

Spleen tissue was obtained at necropsy from a patient with Hodgkin's disease with gross splenic involvement. The tissue was homogenised in Waymouth's medium (Gibco Bio-cult Ltd) and centrifuged at $5000 \mathrm{rpm}$ for five minutes, the supernatant then being removed and diluted to give a protein concentration of about $200 \mathrm{mg} / \mathrm{l}$.

The leucocyte migration technique used was that described by Søberg and Bendixen ${ }^{4}$ with minor modifications. Venous blood $(10 \mathrm{ml})$ was collected from each patient into a sterile polypropylene syringe containing 100 units of non-preserved heparin (Weddel Pharmaceuticals). Then $1 \mathrm{ml}$ of dextran 110 in normal saline (Fisons) was added to sediment red blood cells, the syringe being inverted and suspended for 45 minutes at $37^{\circ} \mathrm{C}$. The plasma was then expelled and the leucocytes separated by centrifugation at $1000 \mathrm{rpm}$ for five minutes. These cells were washed and recentrifuged three times with Waymouth's medium (Gibco Bio-cult Ltd) before being resuspended in an equal volume of the medium. The resultant leucocyte suspension was then drawn up into 20- $\mu 1$ microcaps (Drummond Scientific Co) sealed with Cristaseal (Hawksley and Sons) and centrifuged at $500 \mathrm{rpm}$ for five minutes. The capillary tubes were trimmed to the level of the cells and fixed by silicone grease into Sterilin wells containing Waymouth's medium with $10 \%$ heatinactivated fetal calf serum (Flow Laboratories) as control. Duplicate

\footnotetext{
Academic Division of Medicine, University of Sheffield, Roya Hospital, Sheffield S1 3SR

B W HANCOCK, MB, MRCP, lecturer

LESLEY BRUCE, HNC, medical laboratory scientist

JOHN RICHMOND, MD, FRCP, professor
}

wells were set up with (a) splenic extract at a concentration of $10 \mathrm{mg} / \mathrm{l}$, (b) purified protein derivative of tuberculin (PPD) at $50 \mathrm{mg} / \mathrm{l}$, and (c) Candida albicans extract at $50 \mathrm{mg} / \mathrm{l}$. All wells were sealed with cover slips and incubated for 20 hours at $37^{\circ} \mathrm{C}$. Each test was performed in quadruplicate. The migration area was mapped by projection microscopy and measured by paper plaminetry.

In each experiment migration areas with "antigen" were statistically compared with control migration areas using Student's $t$ test. Significant inhibition of migration was judged to have occurred if $\mathbf{P}<0.05$. An index of migration was also determined by dividing the area of migration with antigen by the area of migration without antigen.

Leucocytes from six patients with lymphoma who showed inhibited migration with Hodgkin's splenic extract were also tested against a similarly prepared and diluted extract of normal spleen (removed at g istrectomy for non-malignant gastric ulcer). Leucocytes from two reacting patients with lymphoma and from two non-reacting normal people were also tested against varying concentrations of splenic extract $(0 \cdot 1-200 \mathrm{mg} / \mathrm{l})$.

Cellular incompetence was also assessed in all patients with lymphoma by intradermal skin testing with multiple recall antigens (Candida albicans, mumps, old tuberculin, streptokinase/streptodornase, and trichophyton). Absence of induration of at least $5 \mathrm{~mm}$ at one or more of the sites of injection at 48 hours was taken as an impaired response.

\section{Results}

The results of the leucocyte migration tests with Hodgkin's spleen extract in 171 patients are shown in the figure. Migration was inhibited in $31(56 \%)$ of the 55 patients with Hodgkin's lymphoma and $19(49 \%)$ of the 39 with other lymphomas. Inhibition was also shown in three $(10 \%)$ of the 29 patients with other malignancy and in only one $(4 \%)$ of the 23 normal volunteers and one $(4 \%)$ of the 25 patients with non-malignant disease.

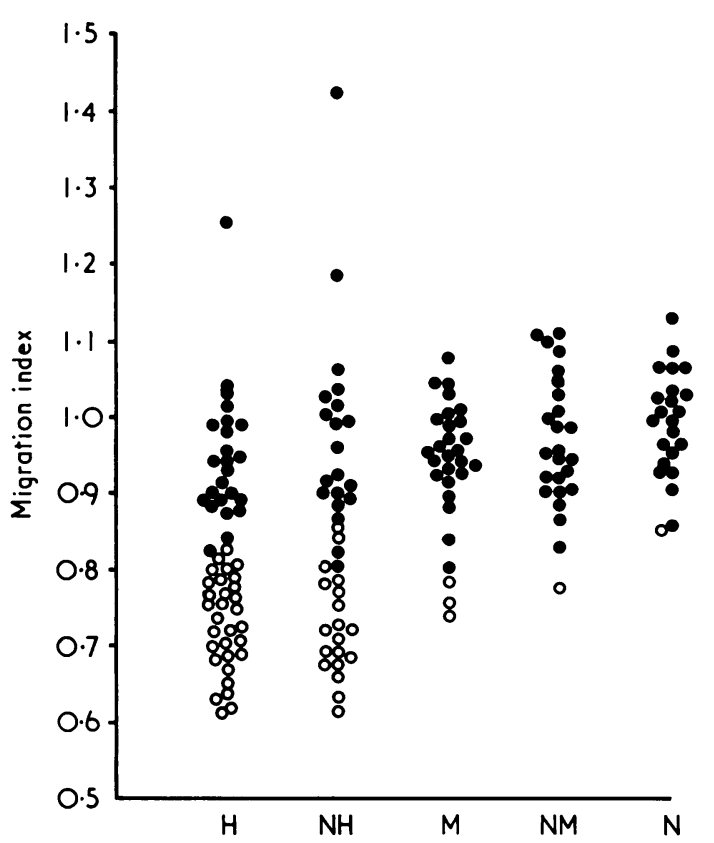

Migration indices in patients not showing (closed circles) and showing (open circles) significant $(\mathbf{P}<0.05)$ inhibition of leucocyte migration with necropsy spleen extract. $\mathrm{H}=$ Patients with Hodgkin's disease. $\mathrm{NH}=$ Patients with spleen extract. $\mathrm{H}=$ Patients with Hodgkin's disease. $\mathrm{NH}=$ Patients with
non-Hodgkin's lymphoma. $\mathrm{M}=$ Patients with non-lymphomatous malignancy. $\mathrm{NM}=$ Patients with non-malignant disease. $\mathrm{N}=$ Normal volunteer 
None of the patients selected from those showing inhibited leucocyte migration with Hodgkin's spleen extract showed inhibited migration when tested with normal spleen extract. In the doseresponse experiments the normal leucocytes did not show inhibited migration at any concentration of spleen extract. The leucocytes from patients with lymphoma showed no significant migration inhibition with concentrations of less than $5 \mathrm{mg} / \mathrm{l}$. At $10 \mathrm{mg} / \mathrm{l}$ significant inhibition occurred but was not further enhanced in higher concentrates of extract (up to $200 \mathrm{mg} / \mathrm{l}$ ). Inhibition of migration with Candida albicans or PPD, or both, was seen in $35(37 \%)$ of the 94 patients with lymphoma but there was no significant correlation between the migration indices with these antigens and those with Hodgkin's spleen extract.

Skin testing gave an impaired response in $20(21 \%)$ of the 94 patients with lymphoma. There was no correlation between this assessment of cellular immunocompetence and reactivity to Hodgkin's spleen extract.

\section{Discussion}

The finding of a splenic factor that inhibits leucocyte migration in patients with lymphoma was not unexpected since other workers have shown possible antigens in non-cultured and cultured Hodgkin's disease tissues. Eshhar et $a l^{5}$ confirmed that the antigen that they showed using immunofluorescence and absorbed tumour antisera in non-cultured spleen was normal tissue ferritin. High serum ferritin levels have been found in patients with leukaemia and Hodgkin's disease ${ }^{6}$ and other neoplasms but may often be related to the non-specific anaemia of neoplastic disease with its associated increase in reticuloendothelial iron stores and decreased serum iron concentration. ${ }^{7}$ Increased ferritin synthesis by neoplastic tissue has been shown in acute leukaemia, ${ }^{8}$ but probably reflects an overall increase in protein synthesis rather than tumour cell overproduction of a specific ferritin.

The nature of the Hodgkin's disease tissue culture antigen of Long et $a l^{2} 910$ has not been established. It is not ferritin but could be a viral component, a tumour or fetal antigen, or a normal tissue factor.

Using the leucocyte migration inhibition technique we have shown sensitisation to a factor present in the spleen of a patient with Hodgkin's disease in over half of the patients with lymphoma who were tested. Sensitisation was seen much less often in other cancer patients, in other inpatients, and in normal people. Sensitisation to normal spleen tissue was not observed and there was no correlation of Hodgkin's splenic factor sensitisation with either Candida albicans or PPD sensitisation, or both, or with cellular immunocompetence. We are now trying to isolate and identify the factor, which may prove to be a helpful diagnostic tool in patients with suspected lymphoma. Its potential prognostic importance and use for detecting disease activity are also being assessed.

We thank Drs C W Potter and I A Carr for helpful criticism, the consultant staff of Weston Park Hospital for access to patients under their care, and the Cancer Research Campaign (Yorkshire Branch) for financial assistance.

\section{References}

1 Order, S E, Porter, M, and Hellman, S, New England fournal of Medicine, 1971, 285, 471.

${ }^{2}$ Long, J C, et al, Proceedings of the National Academy of Sciences of the United States of America, 1973, 70, 1540.

${ }^{3}$ Lancet, 1975, 1, 556.

4 Søberg, M, and Bendixen, G, Acta Medica Scandinavica, 1967, 181, 247.

5 Eshhar, Z, Order, S E, and Katz, D H, Proceedings of the National Academy of Science of the United States of America, 1974, 71, 3956.

${ }^{6}$ Jones, P A E, et al, British fournal of Cancer, 1973, 27, 212.

7 Jacobs, A, and Worwood, M, New England Fournal of Medicine, 1975, 292, 951.

8 White, G P, Worwood, M, and Parry, D H, Nature, 1974, 250, 584.

${ }^{9}$ Long, J C, Aisenberg, A C, and Zamecnik, P C, Proceedings of the National Academy of Sciences of the United States of America, 1974, 71, 2285.

10 Long, I C, Aisenberg, A C, and Zamecnik, P C, Proceedings of the National Academy of Sciences of the United States of America, 1974, 71, 2605.

\title{
Detection of somatic muscle fasciculation on electrocardiograms
}

\author{
D J THOMAS, D O WILLIAMS
}

British Medical fournal, 1976, 1, 557-559

\section{Summary}

Small discrete spikes appearing on the electrocardiogram (ECG) of a man with a pacemaker turned out to be fasciculation potentials picked up from leg muscles. To find out how common these spikes were all routine ECGs made in one month were reviewed. Spike potentials were found in six patients, and in each case they originated from somatic musculature. Spikes could nearly always be detected on ECGs that were recorded subsequently in patients known to have lower motor neurone lesions that produced fasciculation. Thus the presence

Queen Elizabeth Hospital, Birmingham B15 2TH

D J THOMAS, MB, MRCP, senior registrar in neurology

D O WILLIAMS, MB, MRCP, honorary senior registrar in cardiology of these fasciculation spikes may suggest underlying neuromuscular disease; this possibility should be recognised by those who record ECGs so that the spikes are not suppressed by overuse of the filter.

\section{Introduction}

There are three common causes of electrocardiographic (ECG) interference: alternating current artefact if earthing is inadequate; unstable baseline if electrode contact is poor; and "muscle noise" if the patient is cold, not relaxed, or has a tremor. Our interest was aroused by another form of interference which complicated the management of a patient with an indwelling pacemaker. This patient has been reported fully elsewhere; ${ }^{1}$ briefly, he was suffering from paroxysms of dyspnoea and palpitations, and his ECG showed sharp discrete spikes resembling those reported in a case of "runaway pacemaker." $\mathrm{We}$ therefore assumed that the spikes originated from the pacemaker, but they persisted after its replacement. We eventually discovered that they were fasciculation potentials picked up from the man's left leg muscles. 